American Journal of Biochemistry and Biotechnology 6 (3): 231-238, 2010

ISSN 1553-3468

(C) 2010 Science Publications

\title{
Uterus-Relaxing Study of a Sudanese Herb (El-Hazha)
}

\author{
${ }^{1}$ Aimun Abdelgaffar Elhassan Ahmed, ${ }^{1}$ Robert Gaspar, ${ }^{1}$ Arpad Marki, ${ }^{3}$ Andrea Vasas, \\ ${ }^{2}$ Mahmoud Mudawi Eltahir Mudawi, ${ }^{3}$ Judit Hohmann and ${ }^{1}$ George Falkay \\ ${ }^{1}$ Department of Pharmacodynamics and Biopharmacy, Faculty of Pharmacy, \\ University of Szeged, H-6720 Szeged, Eotvos u. 6, Hungary \\ ${ }^{2}$ Department of Therapeutics, Faculty of Pharmacy, Omdurman Islamic University, Sudan \\ ${ }^{3}$ Department of Pharmacognosy, Faculty of Pharmacy, \\ University of Szeged, H-6720 Szeged, Eotvos u. 6, Hungary
}

\begin{abstract}
Problem statement: The aim of this study is to investigate the pharmacological effects of the Methanolic-extract (AH2) of El-Hazha and its sub-fractions. Approach: These investigations were carried out on in vitro isolated uterus preparations from Non-Pregnant (NP) and Late-Pregnant rats (LP). In parallel displacement radio-ligand binding assay was performed for $\beta$-Adrenergic Receptors $(\beta$-ADR). Results: Showed that the herb and its different fractions produced dose-dependent relaxant effect $(\mathrm{p}<0.05$, t-test, $\mathrm{n}=6)$ on uterine contraction elicit by $25 \mathrm{mM} \mathrm{KCl}$ in both NP and LP uteri that affected significantly by fractionation, however, the effect of the most active fraction (AH2-11) was reversed by prior addition of propranolol (non-specific $\beta$-antagonist), but not affected by progesterone pre treatment of the LP rats. In addition, $\mathrm{AH} 2$ only in high concentration displaced isotopes from $\beta$ ADR, this affinity changed markedly by fractionation. Conclusion: We validate the fractionation effect on its relaxant activity and found partial role for $\beta$-ADR on mediating this activity. Future study was recommended to isolate and investigate its active components to enhance this activity or to discover a new novel natural therapeutic agent(s).
\end{abstract}

Key words: Haplophylium tuberculatum, radio-ligand binding assay, $\beta$-Adrenergic Receptors ( $\beta$ ADR), Non-Pregnant (NP), Late-Pregnant rats (LP), Sudanese plant, charles-river laboratories, medicinal and aromatic plants, tocolytic agent, pharmacological effects, progesterone treatment, uterus-relaxing study

\section{INTRODUCTION}

Despite extensive efforts, the incidence of preterm birth has not decreased recent several decades (Monga and Creasy, 1995; Hannah, 2000). Preterm labor is still a health challenge, because there are as yet no effective primary means of its prevention (Koucky et al., 2009).

Tocolytic agents are drugs designed to inhibit the contractions of myometrial smooth muscle cells. The aim of tocolysis is not only to stop uterine contractions and to prevent preterm delivery, but also to decrease the prenatal morbidity and mortality associated with preterm birth (Tsatsaris et al., 2004). The main drugs used as tocolytics are indomethacin and other prostaglandins inhibitors (Vermillion and Landen, 2001), calcium channel blockers such as nifedipine (Pryde et al., 2001; Giles and Bisits, 2007), $\beta$ adrenergic agonists and oxytocin receptors antagonist, while the Medical prevention consists of antibiotic or progesterone administration (Tara and Thornton, 2004).

One of the most well-known mechanism of action through which a tocolytic agent acts was to relax the uterus, so generally any agent has ability to relax the uterus can be considered as a tocolytic agent (Clouse et al., 2007) demonstrates that relaxation of rat myometrium is mediated by $\beta_{2}$-adrenoceptors. also $\alpha 1 / \beta$-adrenoceptor ratio determines not only the spontaneous motor activity of the rat uterus, but also the potency of the agents with tocolytic effect (Zupko et al., 1998).

However, the efficacy and safety of tocolytics are not adequate, new agents are therefore required including substances from natural sources. Many plants have been recently investigated world-wide in the search for tocolytic or uterus-relaxing agent such as Curcuma aeruginosa Roxb. Rhizome (Thaina, 2009), Scutellaria baicalensis root (Shih et al., 2009) and Ficus capensis Thunb (Owolab et al., 2009). 
El-Hazha (Haplophyllum tuberculatum) (Forssk.) A. Juss. (Rutaceae); is an herb indigenous to the northern part of Sudan, North Africa and other areas of the Middle East (Boulus, 1983). Named locally in Sudan as "a plant of all disease", it is to be found in every Sudanese home as an emergency drug that used extensively by old Sudanese in the rural areas. The herb is utilized in Sudan as an antispasmodic, as an antiflatulant, to relieve toothache and to treat allergic rhinitis (Mohamed AH et al., 1996), malaria, gynaecological disorders, asthma, inspiration difficulties, renal disorders and others.

This plant is also well known among herbalists and widely used traditionally in other counties such as Saudi Arabia (Mohammed et al., 1991) and Oman (Mossa et al., 1987).

Its essential oils were investigated for antimicrobial activity by (Al-Burtamani et al., 2005) and were found to cause partial inhibition of the growth of Escherichia coli, Salmonella choleraesuis and Bacillus subtilis to the same extent as gentamycin sulfate.

Its cardiovascular effect were studied by (Mohamed AH et al., 1996), who reported that its aqueous extract significantly decreased the contractility and the heart rate, but did not affect the flow rate of the isolated perfused rabbit heart. This action was not blocked by atropine, but the muscarinic antagonist blocked the fall in blood pressure seen when the extract was administered to anaesthetized cats. The extract also stimulated rabbit aortic strip, rat vas deferens and rat anococcygeus muscles. These adrenergic effects were largely reduced by phentolamine.

Its hepatoprotective activity was investigated on the liver damage induced by paracetamol in mice by (Ali et al., 2001) and proved to be relatively ineffective protecting only $16 \%$ of the animals against the lethal effect of paracetamol $\left(1 \mathrm{~g} \mathrm{~kg}^{-1}\right)$ in comparable to that of the standard hepatoprotective agent silymarin.

When its cytotoxic activity was checked against 11 tumor cell lines, where strong cytotoxic activity was observed (Varamini et al., 1992).

On the other hands and from phytochemical's point of view, some compounds of this Sudanese plant were isolated by (Khalid and Waterman, 1981).

Both its uses to relax the uterus and to treat asthma and inspiration difficulties catalyzed us to carry out this study to evaluate their effects in order to find a new therapeutic agent(s) to aid in solving of two major medical challenges (preterm labor inhibition and asthma control).

Literature survey revealed that the aqueous extract of this plant obviously possess contracting activity, while traditional uses suggested contradictory applications such as muscle relaxant and contracting effect in the same time.

This study was an attempt to proof and evaluate some of its traditional uses in gynaecological area as uterus-relaxing agent and to see the influence of fractionation on its activity.

\section{MATERIALS AND METHODS}

\section{Plant material:}

Crude plant collection and identification: The aerial parts of Haplophylum tuberculatum (El-Hazha) were collected freshly during the 1rst week of November 2008 from their natural habitats in the North part of Sudan (Abu-hamad, Nahr El-Neel State). The voucher specimens (No. M23/08) were identified by Dr. Wai'1 E. Abdalla and Yahia S. Mohamed of Herbarium of Medicinal and Aromatic Plants Research Institute (MAPRI), Khartoum, Sudan, where the specimens were also deposited for future references.

Extraction, fractionation and preparation of the plant material for pharmacological tests: The airdried powdered aerial parts of Haplophylum tuberculatum (AH) (2 $\mathrm{kg})$ were extracted with Methanol for $1 \mathrm{~h}$. The $\mathrm{MeOH}$ extract (AH2) was concentrated and completely dried under vacuum to yields $315 \mathrm{~g}$ of the crude extract which reconstituted in distilled water to get the desired concentration and tested pharmacologically (Ganguly et al., 2007), then fractionated and tested. The most active fraction in each step was selected based on comparing the in vitro pharmacological results, then fractionated and tested. The most active fractions are (AH2-11) $88.31 \mathrm{~g}$, (AH211-4) $4.31 \mathrm{~g}$ and (AH2-11-4-6) 161mg (Fig. 1).

\section{Pharmacological studies:}

Ethical considerations for housing and handling the animals: The animals were treated in accordance with the European Communities Council Directives (86/609/ECC) and the Hungarian Act for the Protection of Animals in Research (XXVIII.tv.32. §). All experiments involving animal subjects were carried out with the approval of the Hungarian Ethical Committee for Animal Research (registration number: IV/17582/2008). Sprague-Dawley rats (Charles-River Laboratories, Hungary) were kept at $22 \pm 3{ }^{\circ} \mathrm{C}$, the relative humidity was $30-70 \%$ and the light/dark cycle was $12 / 12 \mathrm{~h}$. They were maintained on a standard rodent pellet diet (Charles-River Laboratories, Hungary) with tap water available ad libitum. The animals were sacrificed by $\mathrm{CO}_{2}$ inhalation.

Mating of the animals: Mature female (180-200 g) and male (240-260 g) rats were mated in a special mating 
cage. A metal door, which was movable by a small electric engine, separated the rooms for the male and female animals. A timer controlled the function of the engine. Since rats are usually active at night, the separating door was opened before dawn. Within 4-5 h after the possibility of mating, vaginal smears were taken from the female rats and a sperm search was performed under a microscope at a magnification of 1200 times. If the search proved positive, or if smear taking was impossible because of an existing vaginal sperm plug, the female rats were separated and were regarded as first day- pregnant animals.

Isolated organ bath studies: Uteri were removed from non-pregnant (180-200 g), 22-day-pregnant (270-350 g) rats. Muscle rings $5 \mathrm{~mm}$ long were sliced from the uterine horns and mounted in an organ bath ( 8 parallels) containing $10 \mathrm{ml}$ de Jongh solution (in mM: $137 \mathrm{NaCl}$, $3 \mathrm{KCl}, 1 \mathrm{CaCl}_{2}, 1 \mathrm{MgCl}_{2}, 12 \mathrm{NaHCO}_{3}, 4 \mathrm{NaH}_{2} \mathrm{PO}_{4}, 6$ glucose, $\mathrm{pH}$ 7.4). The organ bath was maintained at $37 \mathrm{o}$ $\mathrm{C}$ and carbogen $\left(95 \% \mathrm{O}_{2}+5 \% \mathrm{CO}_{2}\right)$ was bubbled through it. After mounting, the rings were equilibrated for about 1 $\mathrm{h}$ before experiments were undertaken; with a solution change every $15 \mathrm{~min}$. The initial tension was set to about $1.5 \mathrm{~g}$, which was relaxed to about $0.5 \mathrm{~g}$ at the end of equilibration. The tension of the myometrial rings was measured and recorded with a gauge transducer and an S.P.E.L. Advanced ISOSYS Data Acquisition System (Experimetria Ltd., Hungary), respectively. Contractions were elicited with $\mathrm{KCl}(25 \mathrm{mM})$ and cumulative doseresponse curves were constructed in each experiment by addition of plant extract or its fraction(s) in different concentrations (range from $10^{-5}-100 \mu \mathrm{g} \mathrm{ml}^{-1}$ ) alone or in the presence of propranolol $\left(\beta\right.$-blocker) $\left(10^{-6} \mathrm{mM}\right)$. Recording was performed for 5 minutes. Dose-response curves were fitted from areas under curves (AUCs) using Prism 4.0 computer program. $\mathrm{E}_{\max }$ and $\mathrm{EC}_{50}$ values were calculated $\left(\mathrm{E}_{\max }\right.$ : the maximum relaxant effect of extract or its fractions, $\mathrm{EC}_{50}$ : the concentration of extract or its fraction (s) alone which elicits half of the maximum relaxant effect of extract or its fraction (s) or one of its fraction (s).

Progesterone treatment of pregnant rats: The progesterone treatment of the pregnant rats was started on day 15 of pregnancy. Progesterone was dissolved in corn oil and injected subcutaneously every day up to day 21 at a concentration of $0.5 \mathrm{mg}^{0.1} \mathrm{ml} \mathrm{kg}^{-1}$. On day 22, the uteri were collected and the organ bath studies were performed as described above. The experimental data on the non-treated and the progesterone-treated animals were analyzed statistically.

Radio-ligand binding assay:

Membrane preparation: The selected tissue of abundant receptors of interest was rat brain membrane.
Animals were sacrificed by rapid cervical dislocation, both side of the skull were cut from back to forward. The intact brain was expose and removed carefully using forceps. The brain were freed from other tissues and homogenized in ice-cold homogenizing buffer (20 $\mathrm{mM} \mathrm{NaHCO}$ ) in a ratio of 1:5. The homogenate was centrifuged at $15500 \mathrm{rpm}$ speed for $40 \mathrm{~min}$, the resuspended pellets were centrifuged under the same conditions. Finally the pellet were re-suspended in binding buffer $(50 \mathrm{mM}$ tris $+0.5 \mathrm{mM}$ EDTA with $\mathrm{pH}=$ 7.5) and divided into small stock aliquots $2.6 \mathrm{~mL}$ each and frozen at $-70^{\circ} \mathrm{C}$ which diluted and used in radioligand binding displacement assays.

Displacement assay: The affinities of the tested extract and its fractions for $\beta$-adrenergic receptors were measured on above membrane preparation using $[3 \mathrm{H}]$ Dihydroalprenolol (DHA) ( $\beta$-adrenergic antagonist) as radioligand $(\sim 1.5 \mathrm{nM})$.Radioligand were purchased from Amersham International plc (UK). Under standard assay conditions, the final incubation system volume was $300 \mu \mathrm{l}$ consisted of diluted membrane preparation (protein content approximately $0.5-1 \mathrm{mg} \mathrm{ml}^{-1}$ ), radioligand and incubation buffer or with the tested extract or its fractions (its concentration ranging from $10^{-7}-10^{4}$ $\mu \mathrm{g} \mathrm{mL}{ }^{-1}$ ), following the incubation period, the membranes were collected on a Whatman GF/C filter, using a Brandel M24 Cell Harvester. Filters were collected in liquid scintillation vials and the radioactivity was measured with LKB Wallac liquid scintillation counter. The experiment were performed at $25^{\circ} \mathrm{C}$ for $45 \mathrm{~min}$, the nonspecific binding were determined using $10^{-5} \mathrm{M}$ Alprenolol. Displacement experiments were analyzed individually with the computer program Prism 4.0 to determine the inhibition constants $(\mathrm{Ki})$ of the investigated agents.

Statistical analysis: The statistics was done by using Prism 4.0 (GraphPad Software, USA) computer program. For the statistical evaluations, data were collected from at least 6 animals and analyzed by performing two-tailed unpaired t-test to compare the significance mean differences for various results. The differences were considered to be significant at levels of $\mathrm{p} \leq 0.05$.

\section{RESULTS}

Phytochemical extraction and fractionation: The Methanolic-maceration of the plant produced a yield's percentage of $(5.5 \%)$, while the steps of fractionations were highlighted in a summary diagram (Fig.1) emphasizing on that mentioned as most active pharmacologically and used throughout the study. 


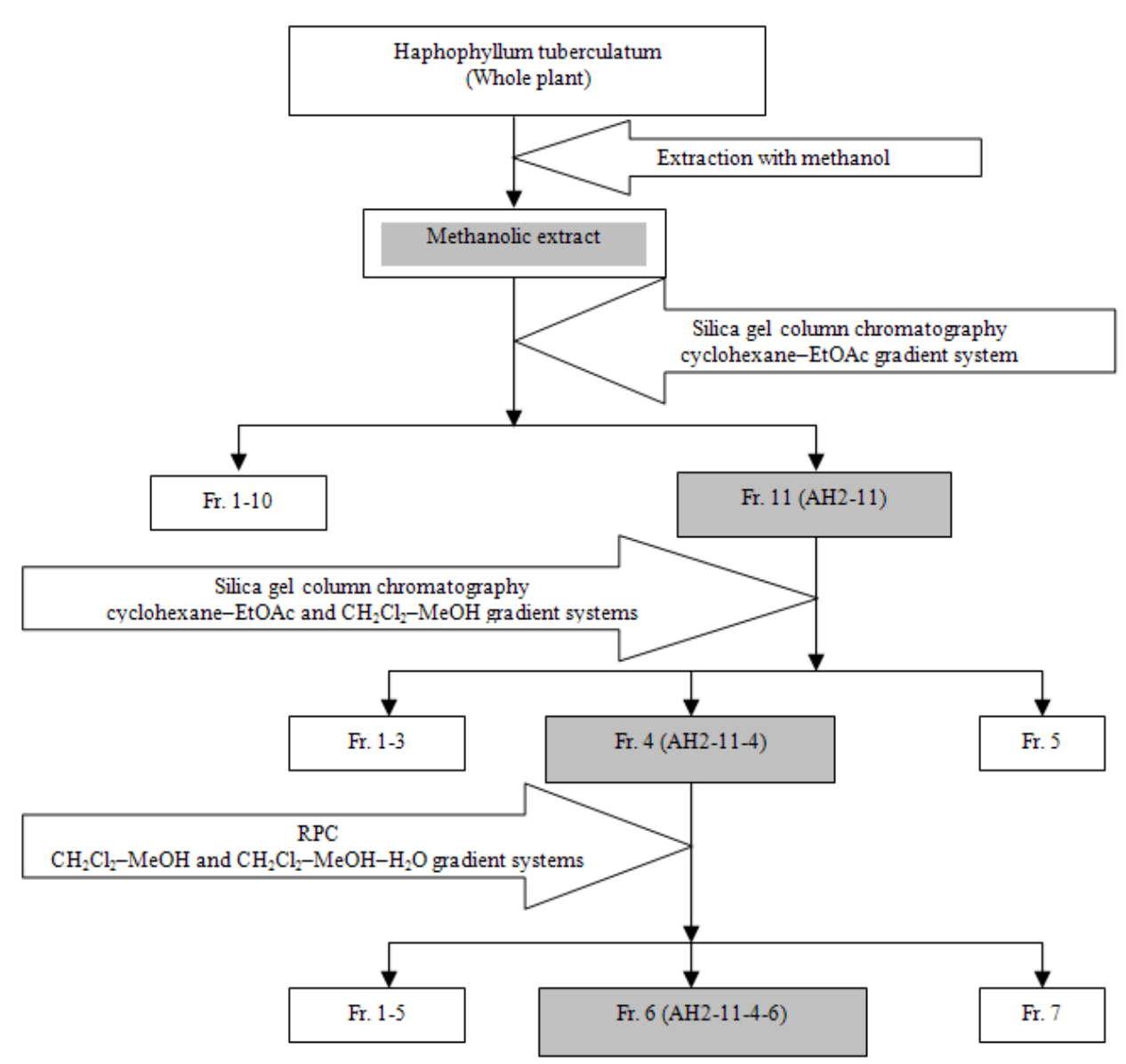

Fig. 1: Diagram illustrated the main steps of Bioactivity-guided fractionation of the Methanolic-extract of El-Hazha emphasized on the most active fractions resulted and used throughout the study.

Table1: The basic effects of the Methanolic-extract on non-pregnant and late-pregnant rat uterus in vitro results, general pilot screening for the direct plant relaxant activity

\begin{tabular}{lll}
\hline Gestation period & $\mathrm{E}_{\max } \pm \mathrm{SEM} \%$ & $\mathrm{EC}_{50} \pm \mathrm{SEM}\left(\mu \mathrm{g} \mathrm{mL}^{-1}\right)$ \\
\hline Non-pregnant & $25.7 \pm 3.6$ & $(2.2 \pm 0.6) \times 10^{-3}$ \\
Late-pregnant & $39.9 \pm 5.8$ & $(0.4 \pm 0.3) \times 10^{-3}$ \\
P-value & 0.094 & $0.027 *$
\end{tabular}

*: $\mathrm{p}<0.05 ; \mathrm{E}_{\max }$ : The maximal relaxing effect of the Methanolicextract against ( $\mathrm{KCl}$-induced contraction); $\mathrm{EC}_{50}$ : The concentration of the Methanolic-extract producing 50\% of their maximal relaxing effect of Methanolic-extract against (KCl-induced contraction) in the system

\section{In vitro pharmacological studies: \\ Rat uterus results:}

Effect of the Methanolic-extract on rat uteri: Basically, the extract showed relaxant activity in NP and LP rat uterus without significant difference in $E_{\max }(p=0.094)$, but with significant difference in $\mathrm{EC}_{50}(\mathrm{p}=0.027)$, Table 1 .
Effect of the different $\mathrm{AH} 2$ fractions after the 2 nd and 3rd fractionation on rat uteri: $\mathrm{AH} 2$ and its fractions showed different activity level on both uteri type (data not shown), while the most active fraction was selected for the next step.

Effect of the most active fractions of $\mathrm{AH} 2$ on rat uteri: In non-pregnant (Fig. 2A and Table 2), the basic AH2 relaxant activity was increased significantly after fractionation while it decreased by further fractionation.

In late-pregnant unlike non-pregnant results, (Fig. $2 \mathrm{~B}$ and Table 2), the extract activity was not significantly affected by different fractionations steps.

After this step the fraction AH2-11 was considered as the most active one and selected for the advanced $\beta$ - adrenergic study using propranolol as standard blocker (Fig. 3 and Table 3) and progesterone treatment (Fig. 4). 
Am. J. Biochem. \& Biotech., 6 (3): 231-238, 2010

Table 2: Relaxant effect of the Methanolic-extract $\mathrm{AH} 2$ and its most active fractions on non-pregnant and late-pregnant rat uterus in vitro results

\begin{tabular}{lllll}
\hline & Non-pregnant & \multicolumn{3}{c}{ Pregnant D 22 } \\
Fraction & $\begin{array}{l}\mathrm{E}_{\max } \pm \text { SEM } \\
(\%)\end{array}$ & $\begin{array}{c}\text { EC50 } \pm \text { SEM } \\
(\mu \mathrm{g} \mathrm{mL})\end{array}$ & $\begin{array}{l}\mathrm{E}_{\max } \pm \text { SEM } \\
(\%)\end{array}$ & $\begin{array}{l}\text { EC50 } \pm \text { SEM } \\
(\mu \mathrm{g} \mathrm{mL})\end{array}$ \\
\hline AH2 & $25.6 \pm 2.6$ & $(2.2 \pm 0.6) \times 10^{-3}$ & $31.7 \pm 5.4$ & $(0.4 \pm 0.3) \times 10^{-3}$ \\
AH2-11 & $81.0 \pm 12.6 *$ & $1.3 \pm 0.6$ & $33.4 \pm 4.5$ & $(4.5 \pm 3.8) \times 10^{-2}$ \\
AH2-11-4 & $58.2 \pm 5.0$ & $(7.8 \pm 5.9) \times 10^{-3}$ & $27.9 \pm 5.2$ & $(4.4 \pm 2.1) \times 10^{-5}$ \\
AH2-11-4-6 & $38.8 \pm 6.3$ & $(6.8 \pm 3.2) \times 10^{-3}$ & $34.9 \pm 3.5$ & $(1.7 \pm 0.7) \times 10^{-4}$ \\
\hline
\end{tabular}

*p $<0.05, \mathrm{AH} 2$ was used as control for its different fractions, $\mathrm{E}_{\max }$ : the maximal relaxing effect of the Methanolic-extract $\mathrm{AH} 2$ or its sub fractions (AH2-11, AH2-11-4 and AH2-11-4-6) against KCl-induced contraction; $\mathrm{EC}_{50}$ : the concentration of the Methanolic-extract $\mathrm{AH} 2$ or its sub fractions (AH2-11, AH2-11-4 and AH2-11-4-6) producing 50\% of their maximal relaxing effect of Methanolic-extract against KCl-induced contraction in the system

Table 3: Propranolol antagonistic effect on the relaxant effect of the most active fraction AH2-11 on isolated non-pregnant and late-pregnant rat uterus in vitro

\begin{tabular}{|c|c|c|c|c|}
\hline \multirow[b]{2}{*}{ Most active Fraction AH2-11 } & \multicolumn{2}{|l|}{ Non-pregnant } & \multicolumn{2}{|l|}{ Pregnant D 22} \\
\hline & $\begin{array}{l}\mathrm{E}_{\max } \pm \mathrm{SEM} \\
(\%)\end{array}$ & $\begin{array}{l}\mathrm{EC} 50 \pm \mathrm{SEM} \\
\left(\mu \mathrm{g} \mathrm{mL}^{-1}\right)\end{array}$ & $\begin{array}{l}\mathrm{E}_{\max } \pm \mathrm{SEM} \\
(\%)\end{array}$ & $\begin{array}{l}\text { EC50 } \pm \text { SEM } \\
\left(\mu \mathrm{g} \mathrm{mL}^{-1}\right)\end{array}$ \\
\hline $\begin{array}{l}\text { Alone } \\
\text { With Propranolol }\left[10^{-6} \mathrm{M}\right]\end{array}$ & $\begin{array}{l}81.0 \pm 12.6 \\
124.1 \pm 16.9\end{array}$ & $\begin{array}{l}1.3 \pm 0.6 \\
(34.6 \pm 8.8) \times 10^{-2}\end{array}$ & $\begin{array}{l}49.5 \pm 3.9 \\
29.5 \pm 3.4 * *\end{array}$ & $\begin{array}{l}(3.9 \pm 3.2) \times 10^{-2} \\
(0.5 \pm 0.4) \times 10^{-3}\end{array}$ \\
\hline
\end{tabular}

*: $\mathrm{p}<0.05, \mathrm{E}_{\max }$ : the maximal relaxing effect of the most active fraction $\mathrm{AH} 2-11$ against $\mathrm{KCl}$-induced contraction; $\mathrm{EC}_{50}$ : The concentration of the most active fraction $\mathrm{AH} 2-11$ producing $50 \%$ of their maximal relaxing effect against $\mathrm{KCl}$-induced contraction in the system

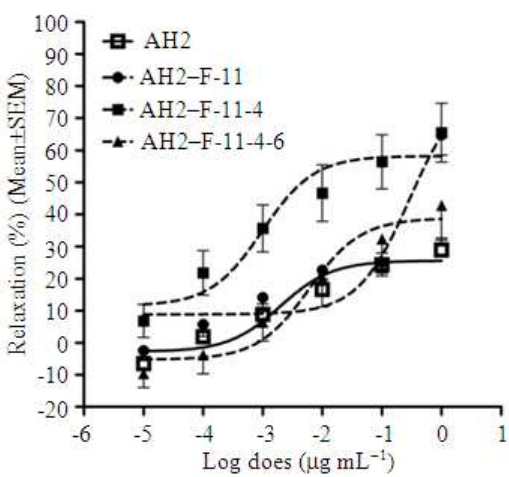

(a)

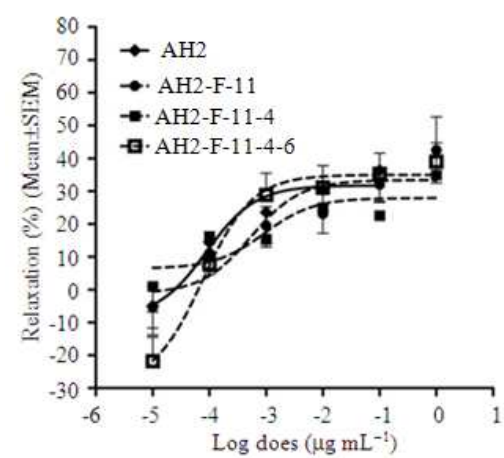

(b)

Fig. 2: Dose-response curves of the relaxing effect of the Methanolic-extract (AH2) (continuous-line) and its most active fractions (dotted-lines) on non-pregnant (a) and late-pregnant (b) rat uterus in vitro against $\mathrm{KCl}$-induced control contractions. Values presented are means of 6-8 observations, while vertical bars denote Standard Errors of the Mean (SEM)

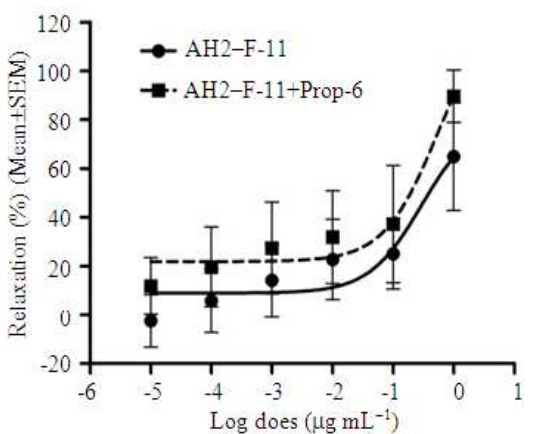

(a)

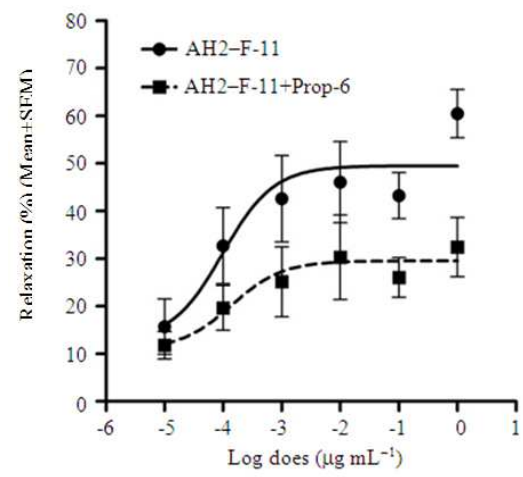

(b)

Fig. 3: Dose-response curves of the most active fraction AH2-11 alone (continuous-lines) and with propranolol $10^{-6}$ (dotted-line) on non-pregnant (a) and late-pregnant (b) on isolated rat uterus in vitro against $\mathrm{KCl}$-induced control contractions. Values presented are means of 6-8 observations, while vertical bars denote Standard Errors of the Mean (SEM) 


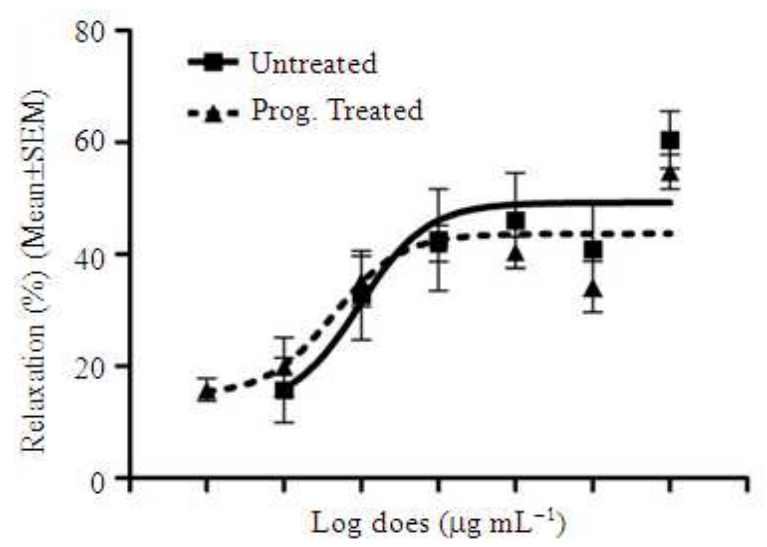

Fig. 4: Dose-response curves of the most active fraction AH2-11, untreated (continuous-lines) and progesterone-treated (dotted-line) on isolated late-pregnant rat uterus (Day22) in vitro against $\mathrm{KCl}$-induced control contractions. Values presented are means of 6-8 observations, while vertical bars denote Standard Errors of the Mean (SEM)

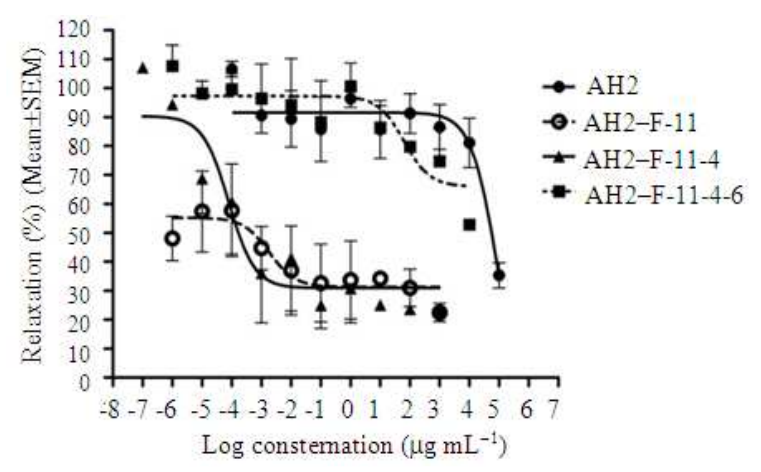

Fig. 5: The displacement curves of $\mathrm{AH} 2$ and its most active fractions on $\beta$-adrenergic receptors using Dihydroalprenolol [3H] DHA as a radioligand and isotopes on rat brain membrane preparation. Values presented are means of 6-8 observations, while vertical bars denote Standard Errors of the Mean (SEM)

Propranolol effect on the relaxant activity of the most active fraction on rat uteri: Propranolol in concentration of $10^{-6} \mathrm{M}$ had no significant effect on neither the curve nor its parameters of the most active fraction AH2-11 on non-pregnant rat uterus (Fig. 3A and Table 3).

On late-pregnant rat uterus (Fig. 3B and Table 3), propranolol in concentration of $10^{-6} \mathrm{M}$ exerts significant effect on the $\mathrm{E}_{\max } \%$ of the curve $(\mathrm{p}=0.0049)$ but with insignificant $(\mathrm{p}=0.184)$ effect on the $\mathrm{EC}_{50}$ of the most active fraction $\mathrm{AH} 2-11$ under investigation.
Effect of AH2-11 on late-pregnant progesteronetreated rat uterus results: The progesterone treatment for late-pregnant rat uterus did not alter significantly neither the $\mathrm{E}_{\max } \%$ nor the $\mathrm{EC}_{50}$ of the curve of the most active fraction $\mathrm{AH} 2-11$ (Fig. 4).

Radio-ligand binding assay: The affinity of the Methanolic-extract and its most active sub fractions from different fractionation steps for $\beta$-adrenergic receptors were tested on rat brain membrane preparation, using Dihydroalprenolol $\left[{ }^{3} \mathrm{H}\right]$ DHA $(2 \mathrm{nM})$ as an isotopes radioligand. All of the ligands displace the radioligand from the target receptor.

The AH2 showed the displacement of the isotopes only in very high concentration $\left(10^{4} \mu \mathrm{g} \mathrm{mL}^{-1}\right)$ with unestimated $\mathrm{Ki}$, while its other sub fractions showed better displacement affinities and the $\mathrm{K}_{\mathrm{i}}$-values of $\mathrm{AH} 2$ $11-4$ and AH2-11-4- 6 were $(1.2 \pm 1.0) \times 10^{-2},(1.1 \pm 1.1)$ $\times 10^{-3}$ and $3.8 \pm 3.8 \mu \mathrm{g} \mathrm{mL}^{-1}$ respectively (Fig. 5).

\section{DISCUSSION}

Plants still a rich drug source (Wahab et al., 2008), El-Hazha, is named locally in Sudan as "a plant of all disease". Due to its extensive use traditionally this plant subjected to different studies in different directions, but the novelty of this study arises from many factors which can be summarized as; deep pharmacological study with detailed assay guided fractionation, while other studies either general or used only the crude extract without fractionation, It involve the use of a pharmacological methods like RLB-assay and It done on both non-pregnant and late-pregnant (D22) rat uterus.

Traditionally El-Hazha is used as an aqueous infusion. In our investigation we made a Methanolicextract (AH2) from the plant, because the polarity of the two solvents are quite similar, the extract contains probably the same components. Previously, the aqueous extract of the plant was investigated by (Mohamed $\mathrm{AH}$ et al., 1996) and gives potent contracting activity. The chloroformic fraction contains non-polar compounds and it was never used traditionally.

In general pilot screening, $\mathrm{AH} 2$ exerts relaxant effect in both uteri with insignificant difference in $\mathrm{E}_{\max } \%$, but the $\mathrm{EC}_{50}$ was significantly differ, while the RLB assay revealed that the extract exerts binding affinity to $\beta$-ADR only in relatively very high concentration, these findings necessitates its fractionation to clarify this affinity.

Fractionation gives different sub-fractions with different efficacies on both isolated uteri, but we deal only with the most active ones. Fractions that produce relaxation $\leq 35 \%$ on NP and $\leq 25 \%$ on LP after first 
fractionation and that produce relaxation activity $\leq 25 \%$ on NP and $20 \%$ on LP after the 2nd fractionation process which calculated as $\mathrm{E}_{\max } \pm \mathrm{SEM} \%$ were mentioned and considered as active. Moreover, the fraction that showed best pharmacological activity was selected for the next steps.

The fractionation effect on the biological extract activity was achieved by relating $\mathrm{AH} 2$ to its most active fractions. In NP uterus, the extract activity was increased significantly $(\mathrm{p}=0.026)$ by fractionation then markedly decreases, but still at a level $(2 \mathrm{X})$ greater.

In LP uterus the activity did not affected significantly by fractionation, but the original extract relaxant activity still exist. In spite that on this stage of pregnancy the sensitivity of the uterus to $\beta$ adrenergic activity was weaker than the non pregnant (Gaspar et al., 2005).

These findings were supported with and confirmed by radio-ligand binding assay experiments results. In which at the beginning fractionation improved $\mathrm{AH} 2$ affinity to $\beta$-ADR, but after the 3rd fractionation process the affinity was deteriorated to a level similar to the $\mathrm{AH} 2$ before fractionation.

We continue the study using the most active sub fraction $\mathrm{AH} 2-11$, because we thought that this relaxant effect may be attributed to synergistic effects of the extract compounds that can be explain by the huge number of compounds that appears in the TLC plate (not shown here).

The selected Fraction AH2-11 as most active one when used to perform further experiments to verify the role of $\beta$-adrenergic receptor in mediating the above mentioned relaxant activity using propranolol as a blocker, both rat uteri revealed that; in NP, propranolol has no effect on the fraction's relaxant activity which may be taken as an evidence of a role of other mechanism(s) involves rather than $\beta$-ADR such as direct muscle effect (Ali et al., 1992) or Ca+-channel blocking activity. But in the LP data the $\beta$-ADR was clearly identified by the propranolol antagonistic effect on the fraction activity in which its dose -response curve was significantly ( $p=0.0049$ ) shifted to the right.

Further conformity test for the $\beta$-ADR role in this relaxation was done by pre-treatment of pregnant rats by progesterone because (Gálik et al., 2008) reported that, Progesterone pre-treatment increases the expression of the $\beta 2$-ADR during pregnancy and alters the effects of $\beta_{2}$-ADR agonists on the pregnant myometrium. In addition, gestagen-induction increases in the myometrial $\beta_{2}$-ADR density and the amount of activated $\mathrm{G}$ proteins coupled to $\beta$-ADRs.

Although (Gaspar et al., 2005) found on the late stage of pregnancy the sensitivity of the uterus to $\beta$ - adrenergic activity was weaker than the non-pregnant, unfortunately the progesterone treatment did not potentiate the $\beta$-receptors sensitivity to this fraction, these findings can be explained by that, the $\beta$-ADR only partially participated in this relaxation besides other possible mechanism(s) or may be hide by the presence of other compounds in this semi-purified fraction.

TLC chromatogram showed the complexity of the active fractions. Even the sub-sub-sub fraction contains large number of structurally related compounds exists in a very small amount, thus their isolation is a very difficult process. These compounds may contribute the various traditional uses and the local name (plant of all diseases) of the plant. Finally, the separation may affect markedly its biological activity due to the well-known plant synergism phenomenon.

\section{CONCLUSION}

Finally we can concluded that, by these findings and demonstration we confirm and proof its mentioned traditional use, even it seems contradictory from the first point of view, The fractionation significantly affect the activity of its Methanolic-extract.

There is a partial role for $\beta$-ADR on mediating this relaxation activity or may be its complete, but inhibited by the existence of other contracting substances that needs further separation and isolation.

The suggested purification may lead to a discovery of a new novel natural therapeutic agent(s) useful to aid solving two major medical problems pre term labour and asthma.

\section{REFERENCES}

Al-Burtamani, S.K., M.O. Fatope, R.G. Marwah, A.K. Onifade and S.H. Al-Saidi, 2005. Chemical composition, antibacterial and antifungal activities of the essential oil of Haplophyllum tuberculatum from Oman. J. Ethnopharmacol., 96: 107-112. DOI: 10.1016/J.JEP.2004.08.039

Ali, B.H., A.K. Bashir and R.A. Rasheed, 2001. effect of the traditional medicinal plants rhazya stricta, balanitis aegyptiaca and haplophylum tuberculatum on paracetamol-induced hepatotoxicity in mice. Phytother Res., 15: 598-603. http://www.ncbi.nlm.nih.gov/pubmed/11746841

Ali, M.B., A.H.M., A.K. Bashir and A.M. Salih, 1992. Pharmacologica Investigation of Haplophyllum tuberculatum. Pharmaceutical Biol., 30: 39-45. DOI: 10.3109/13880209209054628

Boulus, L., 1983. Medicinal Plants of North Africa. Reference Publications Inc., Michigan, pp: 155-158. 
Clouse, A.K., E. Riedel, J.P. Hieble and T.D. Westfall, 2007. The effects and selectivity of betaadrenoceptor agonists in rat myometrium and urinary bladder. Eur. J. Pharmacol., 573: 184-189. http://www.ncbi.nlm.nih.gov/pubmed/17632099

Gálik, M., R. Gáspár, P.Z.K.S. and G. Falkay, 2008. Gestagen treatment enhances the tocolytic effect of salmeterol in hormone-induced preterm labor in the rat in vivo. Am. J. Obstet. Gynecol., 198: 319. http://www.ncbi.nlm.nih.gov/pubmed/18313455

Ganguly, M., M. Kr Borthakur, N. Devi and R. Mahanta, 2007. Antifertility activity of the methanolic leaf extract of Cissampelos pareira in female albino mice. J. Ethnopharmacol.. 111: 688-691. DOI: 10.1016/J.JEP.2007.01.023

Gaspar, R., 2005. Pregnancy-induced decrease in the relaxant effect of terbutaline in the late-pregnant rat myometrium: role of G-protein activation and progesterone. Reproduction, 130: 113-122. http://www.ncbi.nlm.nih.gov/pubmed/15985637

Giles, W. and A. Bisits, 2007. Preterm labour. The present and future of tocolysis. Best Pract. Res. Clin. Obstet. Gynaecol, 21: 857-868. http://www.ncbi.nlm.nih.gov/pubmed/17459777

Hannah, M.E., 2000. Search for best tocolytic for preterm labour. Lancet, 356: 699-700. DOI: 10.1016/S0140-6736(00)02626-X

Khalid, S.A. and P.G. Waterman, 1981. Alkaloid, Lignan and Flavonoid Constituents of Haplophyllum tuberculatum from Sudan. Planta Med., 43: 148-152. http://www.ncbi.nlm.nih.gov/pubmed/17402027

Koucky, M., A. Germanova, Z. Hajek, A. Parizek and M. Kalousova, 2009. News in pathophysiology and management of preterm labour. Ceska Gynekol, 74:

54-63. http://www.ncbi.nlm.nih.gov/pubmed/19408855

Mohamed AH, A.M., A.K. Bashir and A.M. Salih, 1996. Influence of Haplophyllum tuberculatum on the cardiovascular system. Int. J. Pharmac., 34: 213-217. http://informahealthcare.com/doi/abs/10.1076/phbi.3 4.3.213.13208

Mohammed, A., M.M.E.D. Al-Yahya, A. Ibrahim, Al-Meshal and S. Mansour, et al., 1991. (+)-Dihydroperfamine: An Alkaloid from Haplophyllum tuberculatum. Int. J. Pharmac., 29: 268-272. DOI: 10.3109/13880209109082895

Monga, M. and R.K. Creasy, 1995. Pharmacologic management of preterm labor. Semin Perinatol, 19: 84-96.

Mossa, J.S., M.A. Al-Yahya and I.A. Al-Meshal, 1987. Medical Plants of Saudi Arabia. pp: 1. http://digital.library.ksu.edu.sa/ebook598.html
Owolab, O.J., Z.A. Nworgu, A. Falodun, B.A. Ayinde and C.N. Nwako, 2009. Evaluation of tocolytic activity of ethanol extract of the stem bark of Ficus capensis Thunb. (Moraceae). Acta. Pol. Pharm., 66:

293-296.

http://www.ncbi.nlm.nih.gov/pubmed/19645329

Varamini, P.M.D., A. Mohagheghzadeh, M. Soltani and A. Ghaderi1, 1992.Cytotoxic Evaluation of Four Haplophyllum Species with Various Tumor Cell Lines. Pharmaceutical Biol., 45: 299-302. http://life-

sciences.net/stories/206305/Cytotoxic_evaluation_ of_four_Haplophyllum_species_with_various_tum or_cell_lines.html

Pryde, P.G., R.E. Besinger, J.G. Gianopoulos and R. Mittendorf, 2001. Adverse and beneficial effects of tocolytic therapy. Semin. Perinatol, 25: 316-340. http://www.seminperinat.com/article/S01460005(01)80037-9/abstract

Shih, H.C., C.S. Hsuand and L.L. Yang, 2009. In vitro study of the tocolytic effect of oroxylin A from Scutellaria baicalensis root. J. Biomed. Sci., 16: 27. http://www.ncbi.nlm.nih.gov/pubmed/19272127

Wahab, S.I.A., A.W.H. Mohamed, O.Y. Mohamed, M.M.E. Taha, A.B. Abdul and A.S. Al-Zubairi, 2008. Serotonergic properties of the roots of clerodendron capitatum. Am. J. Biochem. Biotechnol., 4: 425-430. ISSN: 1553-3468.

Tara, P.N. and S. Thornton, 2004. Current medical therapy in the prevention andtreatment of preterm labour. Semin. Fetal Neonatal Med., 9: 481-489. http://www.ncbi.nlm.nih.gov/pubmed/15691786

Thaina, P., 2009. Uterine relaxant effects of Curcuma aeruginosa Roxb. rhizome extracts. J. Ethnopharmacol., 121: 433-443. http://www.ncbi.nlm.nih.gov/pubmed/19026735

Tsatsaris, V., D. Cabrol and B. Carbonne, 2004. Pharmacokinetics of tocolytic agents. Clin. Pharmacokinet, 43: 833-844. http://www.ingentaconnect.com/content/adis/cpk/2 004/00000043/00000013/art00001

Vermillion, S.T. and C.N. Landen, 2001. Prostaglandin inhibitors as tocolytic agents. Semin. Perinatol, 25: 256-262. http://www.ncbi.nlm.nih.gov/pubmed/11561913

Zupko, I., A. Marki, R. Gaspar and G. Falkay, 1998. Correlation between alpha1/beta-adrenoceptor ratio and spontaneous uterine motor activity in the postpartum rat. Mol. Hum. Reprod., 4: 921-4. DOI: 10.1093/molehr/4.9.921 